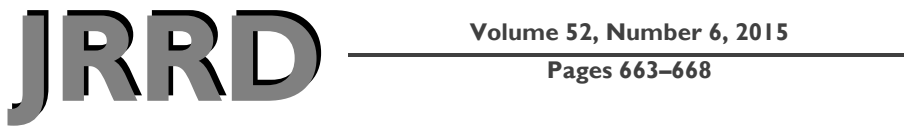

\section{Effects of hyperthyroidism on hand grip strength and function}

\author{
Esra Erkol İnal, MD; ${ }^{*}$ Alparslan Bayram Çarlı, MD; ${ }^{2}$ Sultan Çanak, MD; ${ }^{1}$ Oğuzhan Aksu, MD; ${ }^{3}$ Banu Kale \\ Köroğlu, MD; ${ }^{3}$ Serpil Savaş ${ }^{1}$ \\ ${ }^{I}$ Department of Physical Medicine and Rehabilitation, Süleyman Demirel University, Isparta, Turkey; ${ }^{2}$ Department of \\ Physical Medicine and Rehabilitation, Gölcük Military Hospital, Izmit, Turkey; ${ }^{3}$ Department of Internal Medicine, \\ Division of Endocrinology, Süleyman Demirel University, Isparta, Turkey
}

\begin{abstract}
Hyperthyroidism is a pathologic condition in which the body is exposed to excessive amounts of circulating thyroid hormones. Skeletal muscle is one of the major target organs of thyroid hormones. We evaluated hand grip strength and function in patients with overt hyperthyroidism. Fifty-one patients newly diagnosed with hyperthyroidism and 44 healthy controls participated in this study. Age, height, weight, and dominant hand of all participants were recorded. The diagnosis of hyperthyroidism was confirmed by clinical examination and laboratory tests. Hand grip strength was tested at the dominant hand with a Jamar hand dynamometer. The grooved pegboard test (PGT) was used to evaluate hand dexterity. The Duruöz Hand Index (DHI) was used to assess hand function. No significant differences were found in terms of clinical and demographic findings between the patients with hyperthyroidism and healthy controls $(p>0.05)$. Significant differences were found between the patients with hyperthyroidism and healthy controls regarding PGT and DHI scores $(p<0.05)$. Hyperthyroidism seemed to affect hand dexterity and function more than hand grip strength and seemed to be associated with reduced physical function more than muscle strength. This may also indicate that patients with hyperthyroidism should be evaluated by multidisciplinary modalities.
\end{abstract}

Key words: dominant hand, Duruöz Hand Index, dynamometer, grooved pegboard test, hand dexterity, hand function, hand grip strength, hand rehabilitation, hyperthyroidism, thyroid.

\section{INTRODUCTION}

In patients with hyperthyroidism, the amounts of circulating thyroid hormones increase in the body. While serum concentrations of the two thyroid hormones, triiodothyronine (T3) and thyroxine (T4), increase, levels of thyroid stimulating hormone (TSH) significantly reduce. The thyroid hormones are known to play an essential role in many biological processes in almost every tissue, including protein synthesis, muscle function, energy, and heat production. Fatigue, tremor, weight loss, and general muscle weakness may be seen in about 80 percent of patients with hyperthyroidism [1-2].

Thus, skeletal muscle is one of the major target organs of thyroid hormones; thyrotoxicosis consequently leads to myopathy as well as decreased muscle mass and strength $[1,3]$. In multiple studies, 50 to 62 percent of patients gave a history of muscle weakness, 52 to 68 percent had objective

\footnotetext{
Abbreviations: DHI $=$ Duruöz Hand Index, PGT $=$ grooved pegboard test, $\mathrm{SD}=$ standard deviation, $\mathrm{T} 3=$ tri-iodothyronine, $\mathrm{T} 4=$ thyroxine, $\mathrm{TSH}=$ thyroid stimulating hormone.

*Address all correspondence to Esra Erkol İnal, MD; Süleyman Demirel University, Faculty of Medicine, Department of Physical Medicine and Rehabilitation, Çünür, Isparta, Turkey; +90 246211 9280; fax: +90 2462112830. Email: esraerkol@hotmail.com http://dx.doi.org/10.1682/JRRD.2014.09.0221
} 
evidence of proximal muscle weakness, and 19 percent had distal muscle weakness [4-6]. Myopathy is a feature of thyrotoxicosis, particularly in elderly patients. While thyrotoxicosis is more common among women, symptomatic myopathy is more common among men [7]. In the case of hyperthyroid myopathy, significant dysfunction develops in both proximal and distal skeletal muscles. Decreased shoulder and grip strength were also reported [8]. Nevertheless, proximal muscles seem to be affected much more than distal muscles $[2,4,9]$.

The relationship between overt and subclinical hyperthyroidism and proximal skeletal muscle strength has been investigated previously $[2,4,9]$; however, effects of hyperthyroidism on distal muscles of the upper limb have not yet been demonstrated. Therefore, for the first time, we evaluated hand grip strength, dexterity, and function in patients with primary hyperthyroidism in this study.

\section{METHODS}

Fifty-one patients newly diagnosed with primary hyperthyroidism and 44 healthy controls participated in this cross-sectional study. Patients were excluded if they had pain, stiffness, neuropathy, radiculopathy, or fracture in the dominant upper limb and fingers; had chronic diseases such as rheumatic, cardiovascular, or neuromuscular diseases that may affect functional status; or used medication such as pregabalin and/or gabapentin or statins that have possible adverse effects of dizziness and myalgia and/or myopathy, respectively, that may influence muscle function or motivation. To be included, patients had to have primary hyperthyroidism. None of the participants reported regular sports participation or exercise.

Age, sex, height, weight, body mass index, and dominant hand of the participants were noted. Patients who presented to the outpatient clinic of the Endocrinology Department with symptoms such as palpitation, hyperhidrosis, tremor, and heat intolerance were examined. Hyperthyroidism was suspected by clinical examination findings such as tachycardia, warm and moist skin, and hypertension (especially systolic). Blood samples were obtained in the morning in order to measure serum levels of TSH, free T3, and free T4 [10]. A thyroid function test of free T3, free T4, and TSH levels was carried out by electrochemiluminescence immunoassay method using the fully automatic UniCel DxI 800 immunoassay system (Beckman Coulter Inc; Brea, California). The normal ranges of serum TSH, free
$\mathrm{T} 3$, and free T4 are 0.34 to $4.2 \mu \mathrm{IU} / \mathrm{mL}, 2.5$ to $3.9 \mathrm{pg} / \mathrm{mL}$, and 0.7 to $1.4 \mathrm{ng} / \mathrm{dL}$, respectively. The cutoff value for TSH in diagnosing hyperthyroidism was $\leq 0.33 \mu \mathrm{IU} / \mathrm{mL}$ in this study. Primary hyperthyroidism was diagnosed with suppressed serum TSH and/or elevated free T3 and/or elevated free T4 levels. Antithyroid antibodies were evaluated to determine Graves' disease by electrochemiluminescence immunoassay method using the Cobas e601 analyzer (Roche Diagnostics; Indianapolis, Indiana) [11]. Ultrasonography revealed increased or normal thyroid volume (Graves' disease) and/or focal lesions (toxic qoitre, toxic nodule). Decreased and irregular echogenity of the thyroid gland was accepted as Graves' disease [11]. Thyroid radioactive iodine scintigraphy of the thyroid was performed in order to define Graves' disease and/or focal lesions. According to thyroid radioactive iodine scintigraphy, patients were divided as having or not having Graves' disease [11].

Just after the diagnosis of primary hyperthyroidism in the outpatient clinic, patients were assessed regarding hand grip strength, function, and dexterity. None of the patients used any antithyroid treatments before the hand grip strength, function, and dexterity evaluations conducted by the same investigator (S.Ç.).

A Jamar hand dynamometer (Sammons Preston Inc; Bollingbrook, Illinois) was used to evaluate hand grip strength at the dominant hand. The position of the patient's arm was based on American Society of Hand Therapists recommendations [12]. The patient sat while his or her shoulder was adducted and neutrally rotated with the elbow flexed at $90^{\circ}$ and the forearm and wrist neutrally positioned. Patients squeezed the handle of the dynamometer as hard as possible and maintained the maximal grip contraction for 2 to $5 \mathrm{~s}$. Patients repeated this three times with $30 \mathrm{~s}$ periods between trials. The mean of three trial scores was noted, and lower scores indicate reduced hand grip strength [12].

The grooved pegboard test (PGT) (model 32025, Lafayette Instrument; Lafayette, Indiana) was used to evaluate the dexterity of the hand. The PGT consists of a board with a cup across the top and 25 small holes. Patients were asked to place the 25 small pegs into the 25 small holes as quickly as possible with the dominant hand. The time for totally filling all the holes was noted as the PGT score. As in hand grip strength, the test was conducted three times and the mean of the scores was recorded; longer time indicates worse hand dexterity [13].

The Duruöz Hand Index (DHI) was used to assess hand function. The DHI was categorized into three 
groups with 18 questions: group 1 evaluates activities requiring force and rotational motions, group 2 measures activities requiring dexterity and precision, and group 3 evaluates activities of the flexibility of the first three fingers. Patients were asked to score each item from 0 to 5 according to their experience during the past week, with higher scores indicating worse hand function [14].

\section{STATISTICAL ANALYSES}

Statistical analysis was performed by SPSS version 18 (IBM Corporation; Armonk, New York). The normality of distribution for continuous variables was tested using the Kolmogrov-Smirnov test. Parametric continuous variables were presented as mean \pm standard deviation (SD). Data with abnormal distribution were presented as median and interquartile ranges (the range of values lying between the 25th and 75th centiles). For variables that met parametric test conditions, Student $t$-test was used, and for others, Mann-Whitney $U$ test was used for two-group comparisons. For the evaluation of categorical variables, chi-square test was used. For the evaluation of correlations between the nonparametric variables, Spearman rank correlation test was performed. All $p$-values were calculated as two-sided, and $p<0.05$ was accepted as significant.

\section{RESULTS}

The mean \pm SD ages of the patients with hyperthyroidism and healthy controls were $51.0 \pm 14.2$ and $46.5 \pm$ $12.5 \mathrm{yr}$, respectively $(p>0.05)$. There were no significant differences in terms of sex distribution $(p>0.05)$. The dominant hand was the right, except for three patients with hyperthyroidism and one healthy control $(p>0.05)$. Table 1 summarizes clinical and demographic characteristics, and Table 2 presents laboratory findings of the patients with hyperthyroidism.

The median hand grip strength in patients with hyperthyroidism and healthy controls was $50.0 \mathrm{~kg}$ (range: 43$65 \mathrm{~kg}$ ) and $54.5 \mathrm{~kg}$ (range: $45-81 \mathrm{~kg}$ ), respectively. Regarding hand grip strengths, we found no significant differences between the groups $(p>0.05)$. However, there were statistically significant differences between the patients with hyperthyroidism and healthy controls in terms of PGT and DHI scores $(p<0.05)$. Table 3 presents
Table 1.

Clinical and demographic characteristics of study groups by frequency or mean \pm standard deviation.

\begin{tabular}{lccc}
\hline \multicolumn{1}{c}{ Characteristic } & $\begin{array}{c}\text { Patients with } \\
\text { Hyperthyroidism }\end{array}$ & Healthy Controls & $\boldsymbol{p}$-Value \\
\hline Subjects & 51 & 44 & - \\
Age (yr) & $51.0 \pm 14.2$ & $46.5 \pm 12.5$ & 0.11 \\
Sex & & & 0.85 \\
$\quad$ Male & 16 & 13 & \\
Female & 35 & 31 & \\
Weight (kg) & $70.5 \pm 14.3$ & $74.6 \pm 10.8$ & 0.13 \\
Height (cm) & $164.1 \pm 8.9$ & $164.7 \pm 8.6$ & 0.72 \\
Body Mass Index & $26.2 \pm 4.9$ & $27.5 \pm 3.9$ & 0.15 \\
(kg/m ${ }^{2}$ ) & & & \\
Dominant Hand & & & 0.38 \\
$\quad$ Right & 48 & 43 & \\
Left & 3 & 1 & \\
\hline \hline
\end{tabular}

the DHI, hand grip strength, and dexterity scores of the study groups.

Of the 51 patients with hyperthyroidism, 25 had T3 and/or T4 thyrotoxicosis of Graves' disease. There were no significant differences in terms of the scores of hand grip strength, PGT, and DHI between patients with and without Graves' disease $(p>0.05)$.

There were no significant correlations between TSH, free T4, or free T3 levels and the scores of hand grip strength, DHI, and PGT $(p>0.05)$.

\section{DISCUSSION}

In the present study, we demonstrated that hand grip strength was not significantly different between groups; however, hand dexterity and functional status were impaired in patients with primary hyperthyroidism compared with healthy controls. Graves' disease also seemed not to affect hand grip strength, dexterity, and function compared with patients with primary hyperthyroidism but without Graves' disease.

Skeletal muscle is highly sensitive to excess thyroid hormone but it seems to frequently affect proximal rather than distal muscles [2,4]; our findings on hand grip strength confirm the previous data suggesting this. In Short et al., the reason for this has been explained with oxidative capacity, and they suggest that patients with hyperthyroidism were prone to increased metabolic activity in muscles with high oxidative capacity such as the soleus compared with less oxidative muscles such as 
Table 2.

Laboratory findings of patients with hyperthyroidism $(n=51)$.

\begin{tabular}{llc}
\hline \multicolumn{1}{c}{ Finding } & Median (IQR) & Min-Max \\
\hline Thyroid Stimulating Hormone $(\mu \mathrm{IU} / \mathrm{mL})$ & $0.03(0.01-0.07)$ & $0.01-0.33$ \\
Free Tri-iodothyronine $(\mathrm{pg} / \mathrm{mL})$ & $3.98(3.38-5.75)$ & $2.71-24.90$ \\
Free Thyroxine $(\mathrm{ng} / \mathrm{dL})$ & $1.25(1.05-1.48)$ & $0.71-5.36$ \\
\hline $\mathrm{IQR}=$ interquartile range, $\mathrm{Max}=$ maximum, Min = minimum. & & \\
\hline
\end{tabular}

Table 3.

Hand grip strength and function of study groups. Data presented as median and interquartile range.

\begin{tabular}{lccc}
\hline \multicolumn{1}{c}{ Test } & $\begin{array}{c}\text { Patients with } \\
\text { Hyperthyroidism }\end{array}$ & Healthy Controls & p-Value \\
\hline Jamar Hand Dynamometer (kg) & $50.0(43-65)$ & $54.5(45-81)$ & 0.15 \\
Grooved Pegboard Test (s) & $82.0(37-105)$ & $67.5(59.3-84.3)$ & 0.001 \\
Duruöz Hand Index (score) & $2.0(0-5)$ & $0.5(0-3)$ & 0.04 \\
\hline \hline
\end{tabular}

the plantaris [15]. Nevertheless, underlying mechanisms in muscle wasting and weakness are poorly understood. An increase in muscle protein turnover was reported in patients with hyperthyroidism. Although a net overall increase exists in muscle protein, elevated protein breakdown in muscle is associated with net muscle loss [16].

The muscle weakness in hyperthyroidism is severe and evolves rapidly, but recovery after treatment is fast and good [6]. Hyperthyroid Graves' disease was found to be related to significant changes in handwriting [17]. In contrast, we found no differences in terms of hand function and dexterity, which may be related to handwriting fluidity and fluency between patients with and without Graves' disease. After treatment for hyperthyroidism, a fluent handwriting appeared [17]. Consistent with this result, clinically significant improvements in muscle mass and strength were reported after the treatment of hyperthyroidism [3]. In addition, shoulder and grip strength significantly improved after treatment for hyperthyroidism [8]. On the other hand, it was shown that resistance training in addition to medical treatment increased skeletal muscle performance in patients under both medical and physical therapy compared with patients receiving medical therapy alone [2].

Although muscle strength was accepted as the major indicator of muscle performance, muscular endurance seems to be more closely linked to the ability to apply some daily activities. Arriving at a euthyroid state does not lead patients to improve all aspects of muscle function [18]; Bousquet-Santos et al. showed that muscular endurance did not reach the levels of healthy controls' endurance following medical treatment [2]. Significantly improved grip endurance but not shoulder endurance was also reported in patients treated medically [8]. Therefore, patients with reduced muscle strength due to hyperthyroidism should also be considered for resistance training along with the medical therapy for its positive effect on the functional status and quality of life of these patients. On the other hand, forearm blood flow rose as part of the exercises but there were not any significant differences between the euthyroid and hyperthyroid patients. In the same study, the serum T3 level was found to have no direct effect on skeletal muscle oxygenation or blood flow during dynamic exercise, but it did induce muscle sympathetic nerve activity during fatiguing exercises [19]. How the thyroid hormones affect muscles is still a challenging question.

Because serum T4 levels were found to be correlated with clinical muscle weakness, Duyff et al. suggested a functional muscle disorder in hyperthyroidism [6]. Although we did not find any significant correlations between TSH, free T4, or free T3 levels and the scores of hand grip strength, DHI, and PGT, our data also suggest that there may be a functional muscle disorder in hyperthyroidism because DHI and PGT scores were significantly higher, indicative of impairment, in patients with hyperthyroidism than in healthy controls.

There are several limitations in the present study. We did not know the exact exercise capacity and muscle endurance of the patients, and this could have confounded the assessment of muscle performance. The cross-sectional design, which is not the best way to clarify all the possible associations, also might have lead to false positive or negative results. 


\section{CONCLUSIONS}

Decreased hand function may be linked to impairment in patients' abilities to perform simple daily activities such as self-care tasks. Hyperthyroidism seems to affect hand dexterity and function more than hand grip strength. Our findings regarding PGT and DHI scores suggest that hyperthyroidism is associated with more reduced physical function and hand dexterity than muscle strength. This may also indicate that patients with primary hyperthyroidism, whether with Graves' disease or not, should be evaluated by multidisciplinary modalities. Future studies with larger patient populations and longer follow-up periods should answer whether excess thyroid hormone concentrations worsen hand function and dexterity and should be designed to investigate the possible underlying mechanisms of functional hand impairment.

\section{ACKNOWLEDGMENTS}

\section{Author Contributions:}

Study concept and design: E. Erkol İnal, A. Bayram Çarlı, S. Çanak, O. Aksu, B. Kale Köroğlu, S. Savaş.

Acquisition of data: S. Çanak, O. Aksu, B. Kale Köroğlu. Analysis and interpretation of data: E. Erkol İnal.

Drafting of manuscript: E. Erkol İnal, A. Bayram Çarlı, B. Kale Köroğlu, S. Savaş.

Financial Disclosures: The authors have declared that no competing interests exist.

Funding/Support: This material was unfunded at the time of manuscript preparation.

Institutional Review: Written consent was received from all participants before enrolling in this study. The ethics committee of the Medicine Faculty of Süleyman Demirel University approved the study. Participant Follow-Up: The authors have no plans to notify the study subjects of the publication of this article because of a lack of contact information.

\section{REFERENCES}

1. Ginsberg J. Diagnosis and management of Graves' disease. CMAJ. 2003;168(5):575-85. [PMID:12615754]

2. Bousquet-Santos K, Vaisman M, Barreto ND, Cruz-Filho RA, Salvador BA, Frontera WR, Nobrega AC. Resistance training improves muscle function and body composition in patients with hyperthyroidism. Arch Phys Med Rehabil. 2006;87(8):1123-30. [PMID:16876559] http://dx.doi.org/10.1016/j.apmr.2006.04.017

3. Brennan MD, Powell C, Kaufman KR, Sun PC, Bahn RS, Nair KS. The impact of overt and subclinical hyperthyroid- ism on skeletal muscle. Thyroid. 2006;16(4):375-80.

[PMID: 16646684]

http://dx.doi.org/10.1089/thy.2006.16.375

4. Ramsay ID. Muscle dysfunction in hyperthyroidism. Lancet. 1966;2(7470):931-34. [PMID:4162369]

http://dx.doi.org/10.1016/S0140-6736(66)90536-8

5. Puvanendran K, Cheah JS, Naganathan N, Wong PK. Thyrotoxic myopathy: A clinical and quantitative analytic electromyographic study. J Neurol Sci. 1979;42(3):441-51.

[PMID:512676]

http://dx.doi.org/10.1016/0022-510X(79)90177-1

6. Duyff RF, Van den Bosch J, Laman DM, van Loon BJ, Linssen WH. Neuromuscular findings in thyroid dysfunction: A prospective clinical and electrodiagnostic study. J Neurol Neurosurg Psychiatry. 2000;68(6):750-55.

[PMID: 10811699]

http://dx.doi.org/10.1136/jnnp.68.6.750

7. Amato AA. Endocrine myopathies and toxic myopathies. In: Brown WF, Balton CF, Aminoff MJ, editors. Neuromuscular function and disease: Basic, clinical and electrodiagnostic aspects. Vol. 2. Philadelphia (PA): W. B. Saunders; 2002. p. 1399-1402.

8. Olson BR, Klein I, Benner R, Burdett R, Trzepacz P, Levey GS. Hyperthyroid myopathy and the response to treatment. Thyroid. 1991;1(2):137-41. [PMID:1688015] http://dx.doi.org/10.1089/thy.1991.1.137

9. Nørrelund H, Hove KY, Brems-Dalgaard E, Jurik AG, Nielsen LP, Nielsen S, Jørgensen JO, Weeke J, Møller N. Muscle mass and function in thyrotoxic patients before and during medical treatment. Clin Endocrinol (Oxf). 1999; 51(6):693-99. [PMID:10619973] http://dx.doi.org/10.1046/j.1365-2265.1999.00861.x

10. Devereaux D, Tewelde SZ. Hyperthyroidism and thyrotoxicosis. Emerg Med Clin North Am. 2014;32(2):277-92. [PMID:24766932] http://dx.doi.org/10.1016/j.emc.2013.12.001

11. Gurgul E, Sowinski J. Primary hyperthyroidism — diagnosis and treatment. Indications and contraindications for radioiodine therapy. Nucl Med Rev Cent East Eur. 2011; 14(1):29-32. [PMID:21751169] http://dx.doi.org/10.5603/NMR.2011.0006

12. Hamilton A, Balnave R, Adams R. Grip strength testing reliability. J Hand Ther. 1994;7(3):163-70.

[PMID:7951708] http://dx.doi.org/10.1016/S0894-1130(12)80058-5

13. Ruff RM, Parker SB. Gender- and age-specific changes in motor speed and eye-hand coordination in adults: Normative values for the Finger Tapping and Grooved Pegboard Tests. Percept Mot Skills. 1993;76(3 Pt 2):1219-30. [PMID:8337069] http://dx.doi.org/10.2466/pms.1993.76.3c.1219 
14. Duruöz MT, Cerrahoglu L, Dincer-Turhan Y, Kürsat S. Hand function assessment in patients receiving haemodialysis. Swiss Med Wkly. 2003;133(31-32):433-38. [PMID:14562186]

15. Short KR, Nygren J, Barazzonı R, Levıne J, Naır KS. T(3) increases mitochondrial ATP production in oxidative muscle despite increased expression of UCP2 and -3. Am J Physiol Endocrinol Metab. 2001;280(5):E761-69. [PMID:11287359]

16. Brennan MD, Coenen-Schimke JM, Bigelow ML, Nair KS. Changes in skeletal muscle protein metabolism and myosin heavy chain isoform messenger ribonucleic acid abundance after treatment of hyperthyroidism. J Clin Endocrinol Metab. 2006;91(11):4650-56. [PMID:16940450]

http://dx.doi.org/10.1210/jc.2006-1074

17. Papi G, Botti C, Corsello SM, Ciardullo AV, Pontecorvi A, Hegedüs L. The impact of Graves' disease and its treatment on handwriting characteristics. Thyroid. 2014;24(8): 1218-22. [PMID:24694270] http://dx.doi.org/10.1089/thy.2013.0668

18. Da Nóbrega AC, Vaisman M, De Araújo CG. Skeletal muscle function and body composition of patients with hyperthyroidism. Med Sci Sports Exerc. 1997;29(2):175-80.
[PMID:9044219]

http://dx.doi.org/10.1097/00005768-199702000-00002

19. Ray CA, Sauder CL, Ray DM, Nishida Y. Effect of acute hyperthyroidism on blood flow, muscle oxygenation, and sympathetic nerve activity during dynamic handgrip. Physiol Rep. 2013;1(1):e00011. [PMID:24303102] http://dx.doi.org/10.1002/phy2.11

Submitted for publication October 16, 2014. Accepted in revised form May 14, 2015.

This article and any supplementary material should be cited as follows:

Erkol İnal E, Bayram Çarlı A, Çanak S, Aksu O, Kale Köroğlu B, Savaş S. Effects of hyperthyroidism on hand grip strength and function. J Rehabil Res Dev. 2015; 52(6):663-68.

http://dx.doi.org/10.1682/JRRD.2014.09.0221

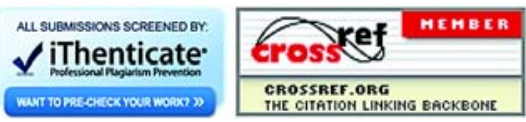

